\title{
PRÉ-REGUISITOS PARA IMPLEMENTAÇÃO DO SISTEMA APPCC EM UMA LINHA DE ALFACE MINIMAMENTE PROCESSADA ${ }^{1}$
}

\author{
Adriano Gomes da CRUZ ${ }^{2, *}$, Sérgio Agostinho $\mathrm{CENCI}^{3}$, Maria Cristina Antun MAIA ${ }^{4}$
}

\begin{abstract}
RESUMO
Boas Práticas de Fabricação (BPF) e Procedimentos Padrão de Higienização Operacional (PPHO) são Programas Pré-requisitos (PPRs) para implementação do sistema APPCC, sendo, em função disto, etapa inicial na adoção de sistemas de garantia de qualidade na indústria de alimentos. Nesse trabalho, foi avaliada uma unidade de processamento mínimo de hortaliças segundo uma auditoria, análises microbiológicas da água, equipamentos, utensílios e manipuladores. Foram verificadas diversas não-conformidades relacionadas à auditoria na unidade produtora. Nas análises microbiológicas foram identificados grupos microbianos em níveis superiores aos estabelecidos pela legislação (variação de $<3->16 \mathrm{NMP} / 100 \mathrm{~mL}$ e $7-2400 \mathrm{NMP} / \mathrm{cm}^{2}$ para coliformes a $35^{\circ} \mathrm{C}$ e a $44^{\circ} \mathrm{C}$, na água e nos equipamentos e/ou utensílios, respectivamente). S. aureus não foi detectado nos manipuladores, enquanto que $E$. coli mostrou-se presente nos manipuladores e ausente na água. Os resultados revelam que a unidade produtora não tem as condições necessárias para a implementação do APPCC, sendo necessárias medidas corretivas, entre as quais, o ajuste do layout do processo, implementação de controle de pragas, treinamento para os manipuladores, além de controle efetivo dos parâmetros operacionais.

Palavras-chave: programas pré-requisitos, APPCC, vegetais minimamente processados.
\end{abstract}

\section{SUMMARY}

REQUIREMENTS FOR HACCP SYSTEM IMPLEMENTATION IN A MINIMALLY PROCESSED PLANT. Good Manufacturing Practices (GMP) and Sanitation Standard Procedures Operation (SSOP) are Pre-requisite Programs (PPRs) for the HACCP system implementation, being the initial step at the adoption of an Assurance Quality System in the Food Industry. A Brazilian produce line was evaluated according to PPRs compliance and microbiological analysis of processing water, equipments/utensils and workers of packing room were performed. Several failures were detected in the auditing and presence of pathogens and microbial groups at values from the Brazilian legislation (range from $<3$ to $>16 \mathrm{MNP} / 100 \mathrm{~mL}$ and $7-2400 \mathrm{MPN} / \mathrm{cm}^{2}$ for total and fecal coliform at the water processing and equipments/utensils, respectively). S. aureus was not detected on the handlers, while $E$. coli was present on them and absent at the water processing. The results indicate the produce unit do not have conditions for the HACCP implementation, being necessary corrective actions to improve the safety of environmental processing, like pest control, food hygiene training and an effective control of standard parameters process.

Keywords: pre-requisite programs, HACCP, minimally processed vegetables.

\section{1 - INTRODUÇÃo}

O processamento mínimo de hortaliças o objetivo de fornecer ao consumidor produtos semelhantes aos comercializados frescos e, ao mesmo tempo, garantir a sua segurança e manter a qualidade nutricional e sensorial, sendo por isso isento de uma etapa efetiva de morte microbiana, como tratamento térmico [18].

Por utilizar matéria-prima de origem vegetal, que está sujeita a diversas fontes de contaminação microbiana ao longo do seu cultivo e processamento, como água de irrigação, manipuladores, solo, equipamentos e utensílios e água, a implementação de um sistema de garantia de qua-

\footnotetext{
${ }^{1}$ Recebido para publicação em 24/1/2005. Aceito para publicação em 23/1/2006 (001464)

${ }^{2}$ Programa de pós-graduação em Ciência de Alimentos do Instituto de Química (IQ). Universidade Federal do Rio de Janeiro (UFRJ)

Rua Sidôneo Paes, 163 /103

CEP 21350-030 - Rio de Janeiro, Brasil

E-mail:food@globo.com

Telefones: (21) 3271-3686/ (21)2595-4901

${ }^{3}$ Embrapa Agroindústria de Alimentos, Avenida das Américas, $n^{\circ} 29.501$

CEP 23020-470 - Guaratiba, Rio de Janeiro (RJ), Brasil

${ }^{4}$ Escola de Quimica (EQ). Universidade Federal do Rio de Janeiro (UFRJ), Bloco E, Sala 203

CEP 21949-900 - Rio de Janeiro (RJ)

*A quem a correspondência deve ser enviada
}

lidade por unidades que processam esse tipo de produto torna-se compulsória.

Programas Pré-Requisitos (PPRs) representam a primeira etapa na obtenção de qualidade assegurada para estabelecimentos que processam e/ou manipulam alimentos. Podem ser definidos como procedimentos ou etapas universais que controlam condições operacionais dentro de uma indústria alimentícia, permitindo a criação de condições ambientais favoráveis à produção de um alimento seguro [9]. Eles incluem elementos que são freqüentemente descritos como Boas Práticas de Fabricação como, por exemplo, limpeza e sanitização, higiene pessoal e do ambiente fabril, projeto higiênico-sanitário da planta e manutenção preventiva. Essas condições estão bem estabelecidas e têm sido empregadas há bastante tempo pelo setor alimentício, de tal forma que qualquer estabelecimento processador de alimentos trabalha de acordo com um destes itens [27].

PPRs não constam como parte integrante do sistema APPCC formal, sendo freqüentemente gerenciados como programas gerais de qualidade da indústria e dirigidos a um produto ou processo específico, e por isso é mais razoável incluí-los dentro de um sistema de qualidade. Ao contrário do APPCC, falhas no seu cumprimento não resultam em ação direta sobre o produto, sendo, por isso, uma diferença essencial entre os mesmos. Entretanto, se um PPR não é conduzido adequadamente, a análise de perigos pode estar 
equivocada e o plano APPCC inadequado, já que Pontos Críticos de Controle (PCCs) serão adicionados, resultando em um aumento da complexidade do plano APPCC [21].

WALLACE e WILLIAMS [27] relatam o exemplo de estabelecimento produtor de alimentos desidratados que elaborou um plano APPCC com 600 Pontos Críticos de Controle por não implementar previamente os programas pré-requisitos.

Boas Práticas de Fabricação (BPF) e Procedimentos Padrão de Higienização Operacional (PPHO) são exemplos universalmente aceitos de PPRs. O primeiro é um programa utilizado para controlar processos e procedimentos de condições operacionais para facilitar a operação de alimentos inócuos, e abrange procedimentos relacionados à utilização das instalações, recepção e armazenamento, manutenção de equipamentos, treinamento e higiene dos trabalhadores, limpeza e desinfecção, controle de pragas e devolução de produtos.

O segundo compreende a descrição completa das atividades específicas necessárias para manter as instalações e utensílios livres de microorganismos patogênicos e com a microbiota deteriorante minimizada, que conseqüentemente previne a contaminação do alimento quando em contato com estes utensílios e instalações, estando incluído no sistema BPF, mas, devido a sua importância, é freqüentemente estudado em separado [16].

Estabelecimentos processadores e/ou manipuladores de produtos alimentícios que adotaram os PRPs antes do sistema APPCC mostraram uma significativa melhora na qualidade higiênico-sanitária e, conseqüentemente, uma elevação de nível de segurança em seus processos, evidenciada pela eliminação de patógenos e pela redução da carga microbiana global [2, 23, 26].

O objetivo deste trabalho é avaliar uma unidade processadora de vegetais minimamente processados, com relação aos Programas Pré-requisitos (PPRs) e PPHO, verificando, com isso, se há condições suficientes para a implementação do sistema APPCC. A linha de alface minimamente processada, por representar o maior volume de vendas da unidade produtora, foi a escolhida para a realização deste estudo.

\section{2 - MATERIAL E MÉTODOS}

O critério de escolha da unidade a ser auditada baseou-se na parceria da mesma com o Projeto Prodetab/ Embrapa. Localizada no Estado de São Paulo, constituise em unidade de pequeno porte e realiza atividades de processamento mínimo de diversos legumes e hortaliças, como alface, couve, cenoura, tomate, saladas mistas etc. A água utilizada no processamento é submetida à etapa de filtração (filtro de areia).

Foram realizadas três visitas à unidade agroindustrial. A linha de processamento de alface minimamente processada foi auditada in loco por meio de check-list elaborado segundo as diretrizes das Portarias 1.428 , de 30 de novembro de 1993, e 326, de 30 de julho de 1997, da Agência Nacional de Vigilância Sanitária, dividida [7, 8] nas seguintes áreas: (i) Instalações, (ii) Operações, (iii) Pessoal, (iv) Controle de Pragas e (v) Registros e Documentação.

Análises microbiológicas foram realizadas na água utilizada nas etapas de lavagem 1, lavagem 2 e sanitização usada no processamento da alface (coliformes a $35^{\circ} \mathrm{C}$, coliformes a $45^{\circ} \mathrm{C}$ e pesquisa qualitativa de Escherichia coli), na superficie da centriífuga e no rolo da esteira, equipamentos e/ou utensílios considerados críticos no processo (coliformes a $35^{\circ} \mathrm{C}$ e coliformes a $45^{\circ} \mathrm{C}$ ) e dos manipuladores que trabalhavam na seção de empacotamento do produto final (pesquisa qualitativa de Escherichia coli e Staphylococus aureus). Todo o procedimento envolvido na coleta, transporte e execução das análises seguiu a metodologia preconizada pela American Health of Public Association [3].

\section{3 - RESULTADOS E DISCUSSÃo}

\section{1 - Processamento mínimo da alface minimamente processada}

As etapas executadas pela unidade produtora no processamento mínimo do alface, estão descritas em um fluxograma conforme mostrado na Figura 1. Foram identificadas dez etapas, a saber: (a) Estocagem da matéria-prima, (b) Recepção / seleção feita de forma manual, (c) Pré-lavagem do produto em detergente específico para vegetais, (d) e (e) Lavagens sucessivas com água, (f) Sanitização com ozônio,

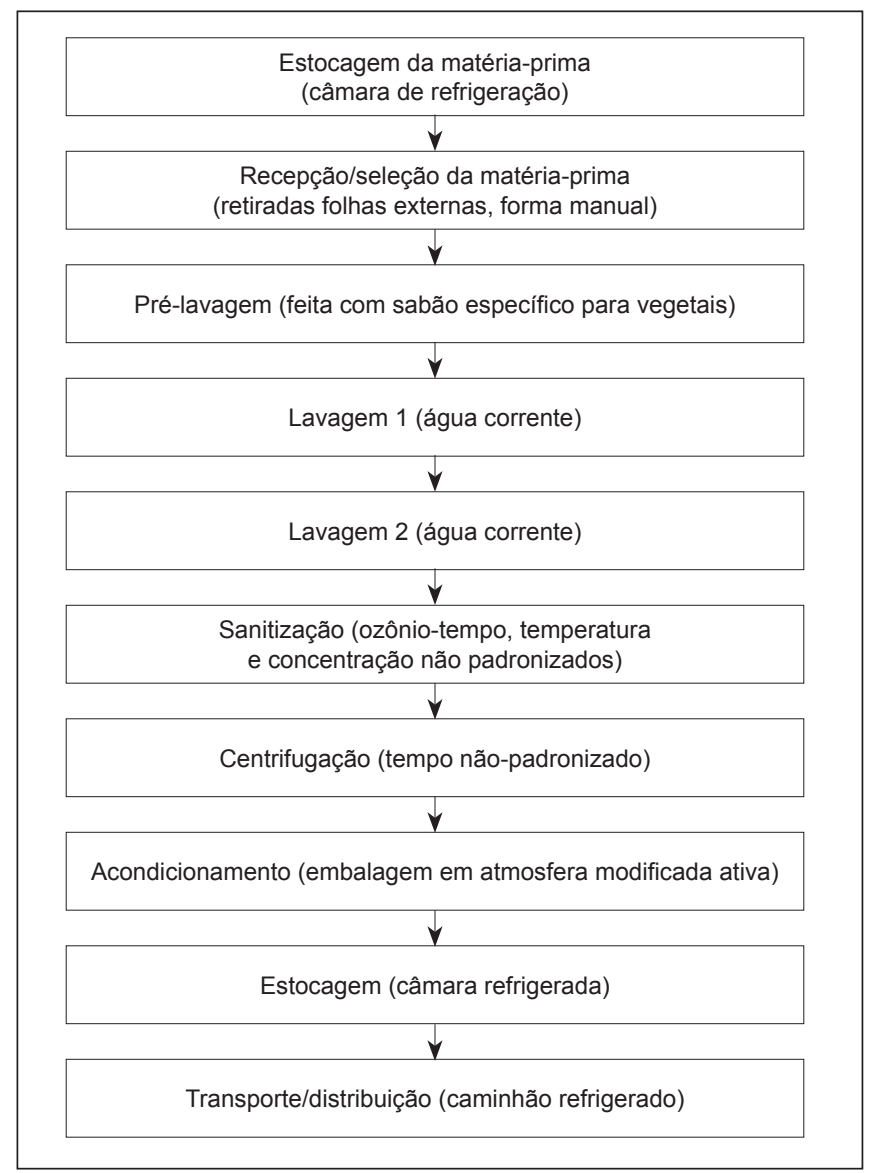

FIGURA 1 - Etapas do processamento mínimo da alface 
(g) centrifugação, (h) acondicionamento, (i) Estocagem refrigerada e (j) Transporte / distribuição.

\section{2 - Auditoria de BPF}

Foram verificadas as seguintes não-conformidades durante a auditoria de BPFs, descritas a seguir:

(1) Instalações: (a) layout do processo inadequado, expresso pela inexistênica da separação entre a área de recepção da matéria-prima das demais áreas, possibilitando o contato do produto processado com a matéria-prima, no ambiente de processamento, propiciando contaminação cruzada; (b) pisos dotados de superfície não-sanitária, observando-se a presença de ressaltos de concreto ásperos, dificultando a operacionalidade e o tráfego durante o processo; (c) inexistência de cobertura para a região externa de recepção da matéria-prima, tornado a mesma vulnerável ao ataque de animais em geral e própria ao contato com sujidades; (d) falhas no revestimento e pintura das paredes e tetos; (e) câmara de refrigeração do produto final em condição higiênico-sanitária estrutural deficiente, com paredes e pisos carecendo de novos revestimentos. $\mathrm{O}$ local é desprovida de lâmpadas com protetores anti-choque e luminárias sem proteção contra quebras na área de processamento; (f) ausência de chiller, para resfriamento da água de processo a $7^{\circ} \mathrm{C}$, mais adequada por razões de segurança; (g) presença de drenos (ralos) sem o devido cuidado sanitário, como sifões e tampas escamoteáveis; e (h) inexistência de área ou antecâmaras antes da entrada das salas de processamento dotadas de dispositivos destinados à assepsia de mãos, e de boxes para lavagem de botas utilizadas pelos manipuladores.

(2) Pessoal: (a) presença de funcionários utilizando adornos, como jóias, anéis e brincos, na área de produção e (b) ausência de treinamentos periódicos em práticas higiênicos-sanitárias de alimentos para os manipuladores.

(3) Operações: (a) conversas demasiadas entre os funcionários durante o processamento do produto; (b) ausência de higienização períodicas das mãos; (c) matériaprima e produto final expostos por demasiado período fora da refrigeração; (d) caixas plásticas de armazenamento do produto final e da matéria-prima fora dos pallets; (e) tempo de centrifugação do produto não-padronizado; e (f) ausência de monitoramento da temperatura, concentração e tempo de contato do sanificante durante o processamento.

(4) Controle de Pragas: (a) Inexistência de programas de controle de pragas por parte da unidade processadora.

(5) Registros e Controles: (a) Inexistência de procedimentos operacionais e instruções claras para padronizar cada atividade do processo, assim como planilhas de controle associadas, normalmente escritas em um manual de BPF; e (b) ausência de PPHO.

SILVA JUNIOR [22] enfatiza a importância da escolha do tipo de piso a ser empregado e recomenda a aplicação de um piso monolítico com características antiderrapantes dotado de único nível o que diminuiria o perigo de acidentes no deslocamento de acessórios (caixas, pallets). O piso ainda deve ter inclinação suficiente para direcionar aos ralos sifonados à água de higienização e simultaneamente impedir a entrada de roedores.

O controle de pragas mostrou-se totalmente inexistente dentro da unidade produtora, podendo realmente acarretar prejuízos para a segurança microbiológica do produto. A total ausência de normatização das operações do processo, como o tempo de centrifugação do produto e a não monitoração dos parâmetros envolvidos na etapa de sanitização (tempo de contato e concentração do sanificante), podem contribuir para a contaminação microbiológica do mesmo. A primeira, ao não retirar totalmente a umidade presente, pode criar condições ambientais propícias para a multiplicação microbiana, e a segunda, realçada por ser a única etapa efetiva de morte térmica no processo.

A segurança microbiológica do produto minimamente processado passa, obrigatoriamente, por um cuidado todo especial com relação às condições higiênicas-sanitárias do pessoal, utensílios e equipamentos envolvidos e da estrutura da instalação. A unidade produtora deve iniciar o processo de implantação de Boas Práticas de Fabricação com medidas imediatas, como: (a) Ajuste no layout de processamento; (b) aquisição de um resfriador para água de processamento; (c) programas de treinamento em higienização de alimentos para manipuladores; (d) adoção de PPHOs sugeridos para os equipamentos/utensílios e manipuladores; (e) programa de monitoramento da qualidade da água utilizada no processamento, bem como a desinfecção da mesma; (f) implementação de medidas visando o controle de pragas; (g) estabelecimento de parâmetros para a etapa de sanitização (concentração, tempo de contato, temperatura do sanificante).

Os resultados encontrados na auditoria de BPFs concordam com trabalhos realizados por outros autores, demonstrando, de forma geral, a falta de comprometimento da indústria de alimentos com relação a programas de garantia de qualidade e consequente segurança do processo.

WALKER, PRITCHARD E FORSYTHE [28] auditaram 122 estabelecimentos de pequeno e médio porte comercializadores de alimentos, em Nottingham, Inglaterra, e contastaram nível de não-conformidade em questões elementares, como uso de refrigeradores domésticos para fins comerciais, controle deficiente de temperatura nas operações e ausência de registros das atividades em 60,5\% locais, 65\% e $40 \%$ do universo pesquisado, respectivamente.

NETO et al. [15], realizando auditorias para verificar o estado de um indústria de beneficiamento de castanha de caju, no Ceará, verificaram que instalações e registros foram os itens que lideraram as não-conformidades, atingindo, também, mais de $50 \%$ do total.

AMARAL et al. [1], ao inspecionarem uma unidade de alimentação e refeição observaram layout impróprio, que possibilitaria contaminação cruzada dos produtos e ausência de procedimentos operacionais padrão para as diversas fases como principais não-conformidades. 
TABELA 1 - Análise microbiológica da água de processamento

\begin{tabular}{|c|c|c|c|c|c|c|}
\hline & \multicolumn{2}{|c|}{$\begin{array}{c}\text { Coliformes a } 44^{\circ} \mathrm{C} \\
\text { (NPM / } 100 \mathrm{~mL} \text { ) }\end{array}$} & \multicolumn{2}{|c|}{$\begin{array}{c}\text { Coliformes a } 44^{\circ} \mathrm{C} \\
\text { (NPM / } 100 \mathrm{~mL} \text { ) }\end{array}$} & \multicolumn{2}{|c|}{$\begin{array}{c}\text { Escherichia coli } \\
\text { (ausência em } 100 \mathrm{~mL} \text { ) }\end{array}$} \\
\hline Lavagem 1 & $>16$ & $>16$ & $>16$ & 7 & Ausência & Ausência \\
\hline Sanitização & $>16$ & $>16$ & $>16$ & 7 & Ausência & Ausência \\
\hline
\end{tabular}

BASTOS [4], auditando indústrias de polpa de frutas no Estado do Ceará, verificou que o layout da fábrica, tipo de piso empregado na linha de processamento e elaboração de procedimentos operacionais também constituíam-se nos principais problemas a serem resolvidos. Como resultado, $53 \%$ das empresas participantes adequaram o piso e paredes a padrões higiênicos-sanitários, 66,6\% investiram na mudança de layout da fábrica, $83 \%$ das empresas adquiriram equipamentos/ utensílios de aço inoxidável e 60\% investiram em um controle integrado de pragas.

\section{3 - Água de processamento}

A Tabela 1 mostra os resultados nas análises microbiológicas da água de processamento. Os resultados encontrados estão em desacordo com a Portaria 1.469, de 29 de dezembro de 2000, do Ministério da Saúde [6], que estabelece como critério microbiológico a ausência de coliformes totais, fecais e Escherichia coli para água, demonstrando uma precária qualidade higiênico-sanitária e inadequação da mesma para o processamento de alimentos.

A provável responsável pelo aumento do NMP de coliformes fecais (4-11 NMP/100 mL) entre as etapas de lavagem e sanitização e coliformes totais entre as etapas de recepção e lavagem (36-59 NMP/100 mL). Sugere-se a instalação de uma etapa de cloração prévia $(200$ ppm) imediatamente posterior à etapa de filtração já existente e a implementação um programa contínuo de monitoramento da qualidade microbiológica da água em questão, assim como a troca contínua da água de tanques de lavagem e sanitização, e o monitoramento da concentração do sanificante.

HOWARD e GONZALEZ [11] advertem que a qualidade da água é extremamente importante, já que ela é veículo para muitos microorganismos patogênicos, e todas as operações nas quais ela participa, como lavagem e enxágüe, merecem atenção especial por parte dos processadores. MCKNIGHT [14] ressalta que a potabilidade da água deve ser assegurada em todo o estágio da cadeia produtiva de alimentos, sendo este parâmetro regularmente monitorado e documentado.

\section{4 - Equipamentos e utensílios}

A Tabela 2 mostra os resultados das análises microbiológicas dos equipamentos/utensílios. Verificou-se um nível de higienização extremamente precário destes, indicando a necessidade de adoção de procedimentos padronizados de sanitização para os mesmos, sendo $100 \%$ dos resultados acima do valor recomendado pela APHA, $2 \mathrm{UFC} / \mathrm{cm}^{2}[3]$. No caso específico da centrífuga, localizada após a etapa de sanitização, isso se reflete diretamente sobre o produto final, comprometendo sua qualidade higiênico-sanitária e segurança. A Figura 1 mostra o Procedimento Padrão de Higienização Operacional (PPHO 1), sugerido para a higienização dos equipamentos.

TABELA 2 - Análise microbiológica de equipamentos e/ou utensílios

\begin{tabular}{lcccc}
\hline & \multicolumn{2}{c}{$\begin{array}{c}\text { Coliformes a } 35^{\circ} \mathrm{C} \\
\left(\mathrm{NMP} / \mathrm{cm}^{2}\right)\end{array}$} & \multicolumn{2}{c}{$\begin{array}{c}\text { Coliformes a 44 } \\
\left(\mathrm{NMP} / \mathbf{c m}^{2}\right)\end{array}$} \\
\hline Coleta 1 & Coleta 2 & Coleta 1 & Coleta 2 \\
\hline Rolo esteira & 240 & 7 & 240 & 7 \\
Centrífuga & $>2.400$ & 7 & $>2.400$ & 7 \\
\hline
\end{tabular}

Os equipamentos, uma vez mal higienizados, representam uma fonte potencial de contaminação. GARG et al. [10], ao realizarem análises microbiológicas em diversos vegetais minimamente processados em linhas de processamento antes e após a passagem sobre equipamentos/utensílios diversos (cortadores, descascadores, fatiadores, centrífugas), verificaram aumento de dois ciclos logarítmicos na contagem microbiana, sendo o cortador de alface $\left(1,8 \times 10^{4}\right.$ para $\left.1,4 \times 10^{6} \mathrm{UFC} / \mathrm{g}\right)$ e o fatiador de cebola $\left(4,0 \times 10^{3}\right.$ para $1,2 \times 10^{5}$ $\mathrm{UFC} / \mathrm{g}$ ) os maiores resultados encontrados, refletindo a fonte de contaminação representada por eles. KANEKO et al. [12] analisaram diversos equipamentos/utensílios em unidades processadoras de vegetais antes e após a sanitização dos mesmos, obtendo as seguintes faixas de valores para coliformes totais: centrífuga: $3,2 \times 10^{2}$ para $1,3 \times 10^{5} \mathrm{UFC} / \mathrm{g}$, fatiador: $1,3 \times 10^{3}$ para $4,0 \times 10^{3} \mathrm{UFC} / \mathrm{g}$, e redes destinadas ao recolhimento de vegetais no tanque de lavagem $2,5 \times 10^{3}$ para $2,0 \times 10^{5} \mathrm{UFC} / \mathrm{g}$. A Figura 2 mostra o Procedimento Padrão de Higienização Operacional (PPHO 1) sugerido para higienização dos equipamentos e/ou utensílios, centrífuga e rolo de esteira.

\begin{tabular}{|c|c|}
\hline Área & Lavagem \\
\hline Objeto & Rolo esteira / Centrífuga \\
\hline Requerimentos higiênicos & Limpeza e desinfecção \\
\hline Princípio ativo/concentração & $\begin{array}{c}\text { Cloro, 200 ppm por 15 min } \\
\text { (BASTOS et al., 1998) }\end{array}$ \\
\hline Instrução de trabalho & $\begin{array}{c}\text { Cobrir quadro elétrico } \\
\text { (apenas centrífuga); } \\
\text { Lavagem com água; } \\
\text { Enxágüe; } \\
\text { Desinfecção com cloro; } \\
\text { Enxágüe final. }\end{array}$ \\
\hline Freqüência & \begin{tabular}{c} 
A cada batelada. \\
\hline Monitoração
\end{tabular} \\
\hline Responsabilidade & $\begin{array}{c}\text { Inspeção visual. Se resultado não } \\
\text { satisfatório, repetir o processo }\end{array}$ \\
\hline Encarregado/supervisor de produção \\
\hline
\end{tabular}

FIGURA 2 - PPHO 1 


\section{5 - Manipuladores}

A Tabela 3 mostra os resultados das análises microbiológicas realizadas nos manipuladores de alimentos da seção de empacotamento da unidade produtora. Não foram detectados S. aureus, porém a presença de E. coli foi verificada em um manipulador. Os resultados demonstraram a precária condição higiênico-sanitária dos manipuladores da linha de empacotamento do produto final, indicando urgente necessidade de estabelecer treinamento em higiene e manipulação de alimentos, já que a presença de $E$. coli no produto final torna o mesmo impróprio para o consumo do ponto de vista higiênico-sanitário [5]. Além disso, é perigo para a saúde pública, já que este não será submetido a nenhum tratamento térmico antes do seu consumo por parte do consumidor. Recomenda-se a adoção de um programa padronizado de lavagem de mãos e a instalação de hand-washings em locais determinados ao longo da linha de produção.

TABELA 3 - Análise microbiológica dos manipuladores

\begin{tabular}{lllll}
\hline & \multicolumn{2}{c}{ Staphylococus aureus } & \multicolumn{2}{c}{ Escherichia coli } \\
\hline & Coleta 1 & Coleta 1 & Coleta 1 & Coleta 1 \\
\hline Manipulador 1 & Ausência & Ausência & Ausência & Ausência \\
Manipulador 2 & Ausência & Ausência & Ausência & Ausência \\
Manipulador 3 & Ausência & Ausência & Ausência & Ausência \\
Manipulador 4 & Ausência & Ausência & Ausência & Presença \\
\hline
\end{tabular}

A importância dos manipuladores na segurança microbiológica dos produtos e processos na indústria de alimentos é fundamental para sucesso de programas de segurança alimentar, na medida em que eles podem ser vias de transmissão de bactérias enteropatogênicas. KANEKO et al. [12] detectaram a presença de E. coli em manipuladores de indústrias de processamento mínimo, em Tóquio. ROSA et al [20] encontraram contagens na faixa de $2,8 \times 10^{2}$ a $2,8 \times 10^{6} \mathrm{UFC} / \mathrm{g}$ de Staphylococus aureus, com $26,9 \%$ de contagem superior a $10^{5} \mathrm{UFC} / \mathrm{g}$ em saladas comercializadas nos supermercados de Campinas (SP) e Belo Horizonte (MG), indicando alto risco para produção de uma toxiinfecção alimentar.

THUNDERG et al [25] encontraram S. aureus em contagens elevadas indicativas de toxiinfecção alimentar, em vegetais minimamente processados vendidos em lojas varejistas nos Estados Unidos. HOWARD e GONZALEZ [11] advertem que os processadores devem prover aos empregados instalações sanitárias adequadas, possuindo papel toalha, sabonete e água potável, aliados a cursos periódicos, a fim de conscientizá-los sobre como identificar sintomas e sinais de infecções alimentares.

Do ponto de vista qualitativo, é de extrema importância haver ações que disseminem corretas práticas higiênicossanitários para os manipuladores por meio de treinamentos periódicos. Isto se dá por causa das próprias características do processamento mínimo, como ausência de tratamento térmico para a efetiva morte dos microorganismos. Dessa forma, estes passam a ter importância fundamental na linha de produção, já que pode ser fonte de contaminação para o produto.
ROBBERTS e SNEED [19] encontraram uma relação positiva entre as práticas de segurança alimentar implementadas nas atividades e o nível de conhecimento recebido em treinamento por manipuladores em auditoria nos restaurantes de Iowa, Estados Unidos. LEIVAS e MASSON [13], ao realizarem avaliação de treinamento em uma unidades industrial alimentícia no Rio Grande do Sul, encontraram índice de satisfação de 80\% por parte dos funcionários após implantação de BPFs e PPHO. REGO et al. [17] analisaram amostras de alimentos, água, utensílios, equipamentos e mãos de manipuladores de uma unidade de nutrição e alimentação hospitalar antes e após treinamento, constatando um decréscimo de $39 \%$ para $8,5 \%$ no quantitativo de amostras que se encontravam em situação higiênico-sanitária precária. SUMMER e ALBRECHT [24], realizando treinamento em segurança alimentar em unidades processadoras de pequeno porte em Nebraska, Estados Unidos, constataram intenção de mudanças de procedimentos de sanitização e BPFs em mais de 50\% dos presentes.

A Figura 3 mostra o Procedimento Padrão de Higienização Operacional (PPHO 2), sugerido a higienização dos manipuladores da seção de empacotamento.

\begin{tabular}{|c|c|}
\hline Área & Empacotamento \\
\hline Objeto & Manipuladores \\
\hline Requerimentos higiênicos & Limpeza e desinfecção \\
\hline Princípio ativo/concentração & $\begin{array}{c}\text { Cloro, 25 ppm por 1 minuto } \\
\text { (BASTOS et al., 1998) }\end{array}$ \\
\hline Instrução de trabalho & $\begin{array}{c}\text { Lavagem mãos e } \\
\text { antebraço com água; } \\
\text { Enxágüe; } \\
\text { Desinfecção com cloro; } \\
\text { Enxágüe final }\end{array}$ \\
\hline Freqüência & $\begin{array}{c}\text { De hora em hora, durante } \\
\text { o horário da produção }\end{array}$ \\
\hline Monitorização & $\begin{array}{c}\text { Inspeção Visual. Se resultado não } \\
\text { satisfatório, repetir o processo }\end{array}$ \\
\hline Responsabilidade & Encarregado/supervisor de produção \\
\hline
\end{tabular}

FIGURA 3 - PPHO II

\section{4 - CONCLUSÕES}

Os resultados obtidos nesse estudo permitem concluir que a unidade produtora de alface minimamente processada não tem as condições necessárias para a implementação do APPCC. Os PPRs foram fundamentais para a identificação de medidas corretivas e/ou preventivas essenciais à segurança do processamento realizado.

Layout do processo era inadequado, propiciando contaminação cruzada, ausência de controle de pragas, inexistência de treinamento para os manipuladores e precário controle dos parâmetros operacionais foram as principais medidas corretivas com impacto direto sobre a segurança do processso de alface minimamente processado detectadas pelos PPRs.

\section{5 - REFERÊNCIAS BIBLIOGRÁFICAS}

[1] AMARAL, C.A.A; LABOISSIERE, L.H.E.S; COLEN, G.; JUNQUEIRA, R.G. Boas Práticas de Fabricação de Ali- 
mentos e Pontos Críticos de Controle em unidades de alimentação e nutrição: um estudo de caso. In: Anais do XVII Congresso Brasileiro de Ciência e Tecnologia de Alimentos, p. 357, Fortaleza (CE), 2000.

[2] ARAMOUNI, F.M.; BOYLE, E.A.E.; VOGT, L.R. Introduction to the Hazard Analysis Critical Control Point (HACCP) concept in a small meat processing plant. Dairy, Food and Environmental Sanitation, v. 16, n. 7, p. 431-439, 1996.

[3] AMERICAN PUBLIC HEALTH ASSOCIATION. Committee on Microbiological Methods for Foods. Compedium of Methods for the Microbiological examination of Foods. $3^{\text {rd }}$ ed., Washigton, 1.219 p., 1992.

[4] Bastos, B.C. Boas Práticas de Fabricação: alternativa para melhoria de qualidade na indústria de frutas. Higiene Alimentar, v. 12, n. 55, p. 65-69, 1998.

[5] BRASIL. MINISTÉRIO DA SAÚDE. AGÊNCIA NACIONAL DE VIGILÂNCIA SANITÁRIA. RDC n. 12, de 2 jan. 2001. Regulamento técnico sobre padróes microbiológicos para alimentos. Disponível em: <http://www.anvisa. gov.br/legis/02_01.html>. Acesso em 22 jul. 2001.

[6] BRASIL. MINISTÉRIO DA SAÚDE. AGÊNCIA NACIONAL DE VIGILÂNCIA SANITÁRIA. Portaria n. 1.469, de 29 dez. 2000. Estabelece normas e padrões de potabilidade da água destinada ao consumo humano. Disponível em <http://www.anvisa.gov.br/portarias/1469_00.html>. Acesso em 22 jul. 2001.

[7] BRASIL. MINISTÉRIO DA SAÚDE. AGÊNCIA NACIONAL DE VIGILÂNCIA SANITÁRIA. RDC n. 326, de 30 jul. 1997. Regulamento técnico sobre as condições higiênico-sanitárias e de Boas Práticas de Fabricação para estabelecimentos produtores/industrializadores de alimentos. Disponível em < http://www.anvisa.gov. br/portarias/326_97.html>. Acesso em 23 jul. 2001.

[8] BRASIL. MINISTÉRIO DA SAÚDE. AGÊNCIA NACIONAL DE VIGILÂNCIA SANITÁRIA. RDC n. 1.428, de 30 nov. 1993. Aprova regulamento técnico para inspeção sanitária de alimentos. Disponível em <http:/www.anvisa.gov. br/portarias/1428_93.html>. Acesso em 23 jul. 2001.

[9] CANADIAN FOOD INSPECTION. Food and Plant of Division Origin. Code of practice for minimally processed ready-to-eat vegetables. 1998.

[10] GARG, N.; CHUREY, J.J.; SPLITTSTOESSER, D.F. Effect of processing conditions on the microflora of fresh-cut vegetables. Journal of Food Protection, v. 53, n. 8, p. 701-703, 1990.

[11] HOWARD, L.R.; GONZALEZ, A.R. Food safety and produce operation: what is the future? Hortscience, v. 36, n. 1, p. 33-39, 2001.

[12] KANEKO, K.; HAYASHIDANI, H.; TAKAHASHI, K.; SHIRAKI, Y.; LIMAWONGPRANEE, S.L.; OGAWA, M. Bacterial contamination in the environment of food factories processing ready-to-eat fresh vegetables. Journal of Food Protection, v. 62, n. 7, p. 800-804, 1999.

[13] LEIVAS, M.K; MASSON, M.L. Aspectos relevantes sobre GMP e PPHO como pré-requisitos para o programa HACCP. In: Anais do XXI Congresso Brasileiro de Microbiologia. Porto Alegre (RS), p. 121, 2002.

[14] MCKNIGTH, S. Issues in water and safety. Food Protection Trends, v. 22, n. 6, p. 504, 512. 2002.

[15] NETO, R.M. da S.; BASTOS, M. do S.R.; FIGUEIREDO, E.A.T de; MAIA, G.A. Inspeção em indústria de beneficiamento da castanha de caju localizada no
Estado do Ceará visando a implementação das Boas Práticas de Fabricação. In: Anais do XVII Congresso Brasileiro de Ciência e Tecnologia de Alimentos. Fortaleza (CE), v. 1, p. 391, 2000.

[16] OLIVEIRA, A.M. de; MASSON, M.L. Terminologia e definições utilizadas nos sistemas da qualidade e segurança alimentar. Boletim da SBCTA, v. 37, n. 1, p. $52-57,2003$.

[17] REGO, J.C. do PIRES, E.F.; MEDINA, G.P. O treinamento como instrumento de melhoria da qualidade higiênica, em uma unidade de alimentação e nutrição hospitalar. Higiene Alimentar, v. 12, n. 66/67, p. 81-86,1996.

[18] REYES, V.G. Improved preservation systems for minimally processed vegetables. Food Australia, v. 48, n. 2, p. 87-90, 1996.

[19] ROBERTS, K.R.; SNEED, J. Status of Prerequisite and HACCP Program implementation in Iowa restaurants. Food Protection Trends, v. 23, n. 10, p. 808-816, 2003.

[20] ROSA, O.O.; CARVALHO, E.P.; DIONIZIO, F.; DIONIZIO, F.; RIBEIRO, A.C. Presença de Staphylococus aureus em vegetais minimamente processados. In: Anais do II Encontro Nacional sobre Processamento Mínimo de Frutas e Hortaliças. Viçosa, p. 50, 2000.

[21] PERBER, W.H.; STEVENSON, K.E.; BERNARD, D.T.; DEIBEL, K.E.; MOBERG, L.J.; HONTZ, L.R.; SCOTT, V.N. The role of Prerequisite Programs in managing a HACCP system. Dairy Food and Environmental Sanitation, v. 18, n. 17, p. 418-423, 1998.

[22] SILVA JUNIOR, E.A. da. Manual de controle higiênico-sanitário de alimentos. São Paulo, Varela, 475 p., 2002.

[23] SORIANO, J.M.; RICO, H.; MOLTO, J.C.; MANES, J. Effect of introduction of HACCP on the microbiological quality of some restaurant meals. Food Control, v. 13, n. 4-5, p. 253-261, 2002.

[24] SUMMER, S.S.; ALBRECHT, J.A. Implementation of food safety and HACCP training for small food processors: a pilot study in Nebraska. Dairy, Food and Environmental Sanitation, v. 15, n. 7, p. 424-429, 1995.

[25] THUNBERG,R.L.;TRANT, T.T.; BENNETT, R.W.; NATTHEWS, R.N.; BELAY, N. Microbial evaluation of selected fresh produce obtained in retails markets. Journal of Food Protection, v. 65, n. 4, p. 677-682, 2002.

[26] TOMÉ, M.M.; VERA, A.M.; MURCIA, M.A. Improving the control of food production in catering establishments with particular reference to the safety of salads. Food Control, v. 11, n. 6, p. 427- 445, 2000.

[27] WALLACE, C.; WILLIAMS, T. Prerequisites: a help or a hindrance to HACCP. Food Control, v. 12, n. 12, p. 235-240, 2001.

[28] WALKER, E.; PRITCHARD, C.; FORSYTHE, S. Hazard Analysis Critical Control Point and Prerequesite Program implementation in small and medium size food business. Food Control, v. 14, n. 14, p. 169-174, 2003.

\section{6 - AGRADECIMENTOS}

Os autores agradecem aos pesquisadores da Embrapa Agroindústria de Alimentos, André Luiz Bonnet Alvarenga e Carlos Alexandre de Oliveira Gomes e à assistente de pesquisa Eliane Rocha, pelo auxílio prestado durante a auditoria na unidade produtora e na realização das análises microbiológicas. Apoio Financeiro: Projeto Prodetab. 